\title{
Novo modelo de cobrança para o uso de recursos hídricos em bacias de rio controladas por reservatórios: aplicação no sistema Engenheiro Ávidos/São Gonçalo - PB
}

O objetivo deste artigo foi aplicar um novo modelo de cobrança pelo uso de recursos hídricos superficiais em um sistema de reservatórios interdependentes no semiárido do Estado da Paraíba. O modelo aplicado apresenta características como: o uso de tarifas baseadas na sazonalidade do sistema; a possibilidade de inibir a prática de reservas e potenciais captações extras de água por parte dos usuários; a contribuição dos usuários em relação a uma parcela dos investimentos previstos na bacia hidrográfica; a diferenciação proporcional de usuários como base no volume outorgado; e o uso de subsídios quando considerado a existência de recursos hídricos oriundos da transposição de outras bacias hidrográficas. O sistema foi analisado de forma integrada via modelo de otimização multiobjectivo, considerando dois cenários possíveis: envolvendo ou não a transposição do Rio São Francisco e, duas situações distintas: outorgas com ou sem medição de vazão. Os resultados demonstraram que os valores cobrados pelo metro cúbico de água são compatíveis com a realidade local e nacional; a prática de reservas e potenciais captações extras de água por parte dos usuários oneram os valores cobrados de forma a incitar o uso mais racional da água. Constatou-se a aplicabilidade do modelo sendo possível redimensionar os valores dos parâmetros utilizados no âmbito do comitê de bacia.

Palavras-chave: Uso racional da água; Gestão de recursos hídricos; Semiárido.

\section{New model of charging for the use of water resources in river basins controlled by reservoirs: application in Engenheiro Ávidos/São Gonçalo system - PB}

\begin{abstract}
The aim of this study was to apply a new charging model for the use of surface water resources in an interdependent reservoirs system in Paraiba semiarid. The model incorporates new methodological elements such as: the interrelationship between water resources granting and charging; the possibility of inhibiting the practice of reserves, via the water granting, and potential extra water uptake by the various users; users' contribution to a portion of the planned investments in the river basin; the proportional differentiation of users based on the volume granted; and the use of subsidies when considering the existence of water resources from the transposition of other watersheds. The system was analyzed, in an integrated way via optimization model, seeing two possible scenarios: either involving or not the water transposition from the São Francisco River and, two distinct situations: water demands with or without flow measurement. The results demonstrated that the amounts charged by the cubic meter of water use are compatible with the ones of local and national levels; the practice of reservation of water, via grants, and potential extra water intake by the users increases the amounts charged encouraging more rational use of water. In addition, the proposed water charging model can be applied in any watershed, being possible to resize the used parameter values via a more participatory and democratic process within the river basin Committee.
\end{abstract}

Keywords: Rational use of water; Water resources management; Semiarid.

Topic: Engenharia de Recursos Hídricos

Reviewed anonymously in the process of blind peer.

Valterlin da Silva Santos

Universidade Federal de Campina Grande, Brasi

http://lattes.cnpq.br/4740303724015282

http://orcid.org/0000-0002-4789-2937

valterlin@yahoo.com.br

Enéas Dantas da Silva Neto (iD

Universidade Federal de Campina Grande, Brasil

http://lattes.cnpq.br/8236524344695542

http://orcid.org/0000-0002-0101-2842

professoreneasneto@gmail.com

Wilson Fadlo Curi (D)

Universidade Federal de Campina Grande, Brasil

http://lattes.cnpq.br/4941338019932170

http://orcid.org/0000-0002-7024-7127

wfcuri@yahoo.com.br

1

DOI: 10.6008/CBPC2179-6858.2020.007.0023
Received: 02/12/2020

Approved: 22/12/2020
Referencing this:

SANTOS, V. S.; SILVA NETO, E. D.; CURI, W. F.. Novo modelo de cobrança para o uso de recursos hídricos em bacias de rio controladas por reservatórios: aplicação no sistema Engenheiro Ávidos/São Gonçalo - PB. Revista Ibero Americana de Ciências Ambientais, v.11, n.7, p.253-270, 2020. DOI: http://doi.org/10.6008/CBPC2179$\underline{6858.2020 .007 .0023}$ 


\section{INTRODUÇÃO}

A região nordeste do Brasil vivencia, desde 2012, um dos mais prolongados períodos de estiagem. Os volumes armazenados na grande maioria dos reservatórios de captação de águas superficiais; uma das principais fontes de água da região, cujo embasamento é, na sua maioria, cristalino; atingiram níveis críticos, o que tem preocupado e mobilizado usuários e gestores de toda região em torno da questão da escassez de recursos hídricos e, consequentemente, do armazenamento e gestão destes recursos.

Por outro lado, observa-se a aplicação crescente das diretrizes da Política Nacional de Recursos Hídricos (PNRH) via os instrumentos estabelecidos na Lei 9.433/97 em bacias hidrográficas de todo país, em especial a outorga e cobrança pelo uso dos recursos hídricos visando obter uma maior eficiência na utilização desses recursos, assim como arrecadar fundos que permitam os investimentos em melhorias junto às bacias hidrográficas onde o sistema de cobrança for implantado.

É notório que, apesar da Lei 9.433/97 prover o marco legal para implantação de tais mecanismos de gestão, um dos problemas centrais de todo o processo repousa na existência de complexas relações políticas, sociais, ambientais e econômicas de cada sistema hídrico e seus diversos usuários. Tudo isso tem gerado barreiras para a implantação dos instrumentos da referida lei, principalmente ao dificultara criação de sistemas de cobrança pelo uso de recursos hídricos mais eficientes e que, ao mesmo tempo, sejam capazes de refletir o seu verdadeiro objetivo de gestão, estimular o uso mais racional. O que se pode observar é que os atuais modelos instituídos, implantados e discutidos na literatura especializada como Dias et al. (2010), ANA (2014), Finkler et al. (2015), Acserald et al. (2015), Gama Engenharia (2016), Vera et al. (2017) e OCDE (2017), nem sempre conseguem contemplar os aspectos específicos da outorga e cobrança pelo uso dos recursos hídricos de forma direta, integrada e transparente.

Além disso, na maior parte dos casos, principalmente nas bacias hidrográficas federais, os modelos nem sempre refletem objetividade, parcimônia, transparência, completeza (potencial de reajustes a novas situações) e simplicidade em relação ao entendimento de seus aspectos metodológicos, tornando-as ferramentas complexas, o que de certa forma tem dificultado a implantação dos sistemas de cobrança pelo uso dos recursos hídricos em todo o país.

Neste sentido, após uma análise dos diversos modelos de cobrança pelo uso dos recursos hídricos no país, Silva Neto (2018) propõe um modelo de cobrança pautado, dentre outros aspectos, pela objetividade, parcimônia, completeza e transparência em relação aos seus elementos metodológicos e operacionais. Ao analisar, principalmente, os modelos implantados em bacias hidrográficas federais, o autor amplia a análise da cobrança incorporando a sua proposta aspectos inovadores como: a vinculação da outorga de direito com a cobrança pelo uso; o uso de tarifas baseadas na sazonalidade do sistema de recursos hídricos; a possibilidade de inibir a prática de reservas hídricas, via outorga, e potenciais captações extras de água por parte dos diversos usuários; a contribuição dos usuários em relação aos investimentos previstos na bacia hidrográfica; a diferenciação proporcional de usuários como base no volume outorgado; e o uso de subsídios quando considerado a existência de recursos hídricos oriundos da transposição de outras bacias 
hidrográficas.

Assim sendo, o objetivo deste artigo foi aplicar o modelo de cobrança pelo uso de recursos hídrico superficial proposto por Silva Neto (2018) em um sistema de recursos hídricos controlado por reservatórios interdependentes (Engenheiro Ávidos e São Gonçalo) na Bacia Hidrográfica dos Rios Piancó-Piranhas-Açu (BHRPPA) localizada no semiárido paraibano. Para tanto, utilizou-se o modelo de otimização quantitativo multiobjectivo desenvolvido por Santos et al. (2011) de forma a obter as informações operacionais necessárias para a aplicação do modelo de cobrança.

A escolha do sistema hídrico se deu em virtude de o mesmo ser controlado por reservatórios interdependentes e enfrentar frequentemente problemas de escassez. Além do fato de que na BHRPPA ainda não foi implementada a cobrança pelo uso dos recursos hídricos a luz da Lei 9.433/97 e que o sistema em questão irá receber as águas do Eixo Norte do Projeto de Integração do Rio São Francisco (PIRSF).

\section{MATERIAIS E MÉTODOS}

\section{Modelo de cobrança pelo uso dos recursos hídricos}

Ao longo da literatura especializada, diversas são as críticas em relação aos modelos de cobrança pelo uso dos recursos hídricos. Dentre elas, destacam-se: 1 . O caráter meramente arrecadatório enquanto objetivo principal, destacado por Hartmann (2010); 2. A baixa capacidade de suprir financeiramente o sistema de gestão da bacia, argumentam Hartmann (2010), Sousa et al. (2015), Finkler et al. (2015) e Gama Engenharia (2016); 3. A ausência de efeito incitativo da cobrança ao uso racional, conforme apontam Hartmann (2010), ANA (2014) e Acselrad et al. (2015); 4. A relação entre a escassez dos recursos hídricos e seus efeitos sobre as outorgas e a cobrança, de acordo com Thomas (2002) e Gama Engenharia (2016); 5. A baixa aceitabilidade pública e política, reduzida simplicidade conceitual, ausência de transparência, dificuldades na implantação e operação das metodologias, conforme Dias et al. (2010).

Neste sentido, visando maior parcimônia, objetividade, transparência, completeza e indução ao uso racional dos recursos hídricos superficiais, Silva Neto (2018) estruturou seu modelo de cobrança pelo uso dos recursos hídricos basicamente de acordo com sete componentes com valores expressos, em R\$̧, conforme as equações de 1 a 8 :

$$
\begin{aligned}
& \mathrm{VTC}=\mathrm{V}_{\text {out }}+\mathrm{V}_{\text {cap }}+\mathrm{V}_{\text {tra }}+\mathrm{V}_{\text {lan }}+\mathrm{V}_{\text {ges }}+\mathrm{V}_{\text {min }}+\mathrm{V}_{\text {na }} \\
& \text { No qual: }
\end{aligned}
$$




$$
V_{n a}=\left\{\begin{array}{cc}
B_{n a} \cdot Q_{\text {out }} & \text { sem medição de vazão com garantia igual a } 100 \% \\
B_{\text {na }} \cdot Q_{\text {for }} & \text { sem medição de vazão com garantia menor a } 100 \% \\
B_{\text {na }} \cdot Q_{\text {med }} & \text { quando houver medição da vazão }
\end{array}\right.
$$

Sendo: VTC o valor total da cobrança (Em R\$); Vout valor da componente outorga (Em R\$); $V_{\text {cap }}$ o valor da componente captação (Em R\$); $V_{\text {tra }}$ o valor da componente transposição ( $E m R \$$ ); $V_{\text {lan }}$ O valor da componente lançamento de efluentes (Em R\$); $V_{\text {ges }}$ o valor da componente gestão (Em R\$); $V_{\min }$ o valor da componente mineração (Em $R \$$ ); $V_{\text {na }} O$ valor da componente nível de armazenamento de água do sistema (Em R\$); Qout o volume outorgado mensal (em $\mathrm{m}^{3}$ ) (Em R\$); PPU out o preço público unitário do $\mathrm{m}^{3}$ outorgado a ser definido pelo Comitê de Bacia Hidrográfica (CBH) (Em

$\mathrm{R} \$ / \mathrm{m}^{3}$ ); $\mathrm{K}_{\mathrm{g}}$ o coeficiente relativo aos níveis de garantias de atendimento da outorga; $\mathrm{K}_{\mathrm{e}} \mathrm{O}$ coeficiente relativo a eficiência do uso (O valor deste coeficiente é determinado com base no tipo de tecnologia empregada nos sistemas hidráulicos); $\mathrm{K}_{\mathrm{c}} \mathrm{o}$ coeficiente relativo ao enquadramento de classe, conforme legislação; e $\mathrm{F}_{\mathrm{m}} \mathrm{o}$ coeficiente relativo a utilização ou não do medidor de vazão, também chamado de fator medição; $Q_{\text {med }}$ o volume medido mensalmente; $K_{\text {var }}$

o coeficiente de variabilidade (A partir deste coeficiente, pode-se determinar a variabilidade admitidas (Margem de

erro) em cada tipo de atividade. Ou seja, erros podem ser admitidos entre os valores da diferença entre o volume outorgado e o volume medido. Por exemplo, para a agricultura foi admitida margem de erra de $30 \%$ para mais ou para menos); PPU medo preço público unitário da medição; Qtraé o volume de entrada da transposição em $\mathrm{m}^{3} / \mathrm{mês} \mathrm{no}$

sistema; Ku o coeficiente de diferenciação de usuário em relação ao volume outorgado (Determinado com base na participação relativa do volume outorgado de cada usuário no volume outorgado total do sistema de recursos hídricos); PPUtra o preço público unitário do $\mathrm{m}^{3}$ da transposição; 'Sub' é o subsídio governamental; CDBo a concentração de $\mathrm{DBO}_{5,20}$; PPU lan o preço público unitário do lançamento; $\mathrm{Fg}_{\mathrm{g}}$ coeficiente de contribuição em termos percentuais dos usuários em relação aos investimentos considerados (calculado a partir da contribuição, em termos percentuais, atribuída aos usuários em relação ao volume total dos investimentos previstos no sistema de recursos hídricos); VPLinv o valor presente líquido dos investimentos totais do plano de investimentos da bacia ou da sub-bacia (Em R\$);

ARREC_LIQ ${ }_{t+1}$ o saldo líquido acumulado da arrecadação com a cobrança em $R \$$; ' $n$ ' é o número de meses considerados no cálculo do VPLinv; $Q_{\text {are }}$ o volume de água captada na retirada de areia em $\mathrm{m}^{3}$; PPU min o preço público unitário para mineração em $\mathrm{R} \$$; " $U$ ” o teor de umidade da areia produzida; $\mathrm{B}_{\text {na }}$ a bandeira tarifária referente ao nível de armazenamento de água do sistema (Calculada a partir do nível de armazenamento de água no sistema de recursos hídricos); e Qfor o volume em $\mathrm{m}^{3}$ fornecido.

É importante destacar que a UPHAP é só uma das 12 sub-bacias da BHRPPA, de modo, que, para cálculo da componente $V_{\text {tra, }}$ do modelo de cobrança considerou-se apenas o volume de águas da transposição do Rio São Francisco efetivamente utilizado pelo sistema hídrico analisado (SILVA NETO, 2018). Assim:

$$
\mathrm{Q}_{\text {tra }}=\left(\mathrm{Q}_{\text {tra_ent }}-\mathrm{Q}_{\text {saída }}\right)
$$

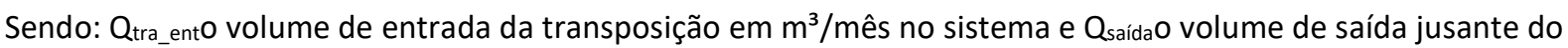
sistema em $\mathrm{m}^{3} / \mathrm{mês.}$

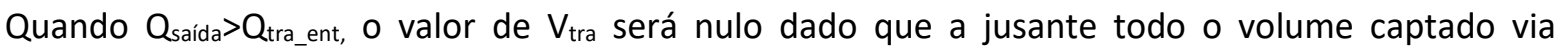
transposição está sendo liberado para usuários não pertencentes ao sistema considerado. De acordo com Silva Neto (2018), essa adaptação foi necessária para efeito de aproximação no cálculo da componente $V_{\text {tra }}$ e, consequentemente, do VTC.

\section{Cenários estudados}

Foram analisados dois cenários distintos para o período considerado, conforme destacado no Quadro 1. No cenário C1 o modelo foi aplicado desconsiderando o volume de recursos hídricos relativo ao PIRSF. Já o cenário C2 contemplou a presença das águas do PIRSF. Tal distinção entre os respectivos cenários se fez necessária, haja vista que a sub-bacia analisada é uma das portas de entrada do eixo norte no estado da Paraíba sendo parte integrante e estratégica do PIRSF, que se encontra em fase de conclusão, refletindo o cenário atual e futuro do sistema de recursos hídricos. 
Novo modelo de cobrança para o uso de recursos hídricos em bacias de rio controladas por reservatórios: aplicação no sistema Engenheiro

Quadro 1: Situações e cenários estudados.

\begin{tabular}{lll}
\hline Situação/Cenário & Cenário 1 (Sem transposição PIRSF) & Cenário 2 (Com transposição PIRSF) \\
\hline Situação 1 (Sem medição de vazão) & S1-C1 & S1-C2 \\
\hline Situação 2 (Com medição de vazão) & S2-C1 & S2-C2 \\
\hline
\end{tabular}

Para cada um dos cenários descritos acima, duas situações foram consideradas e simuladas: situação S1, onde se considerou a ausência de medidor de vazão e situação S2, que levou em conta a medição de vazão por parte dos usuários. Metodologicamente essa distinção se fez necessária, haja vista a preocupação em refletir ao máximo as características peculiares do modelo de cobrança proposto por Silva Neto (2018), principalmente em se tratando da diferenciação do valor cobrado em função da presença e da ausência de medidor de vazão.

\section{Descrição do Sistema Estudado}

Os reservatórios Engenheiro Ávidos e São Gonçalo estão inseridos na BHRPPA mais precisamente na Unidade de Planejamento Hidrológico do Alto Piranhas (UPHAP) no Estado da Paraíba (Figura 1).

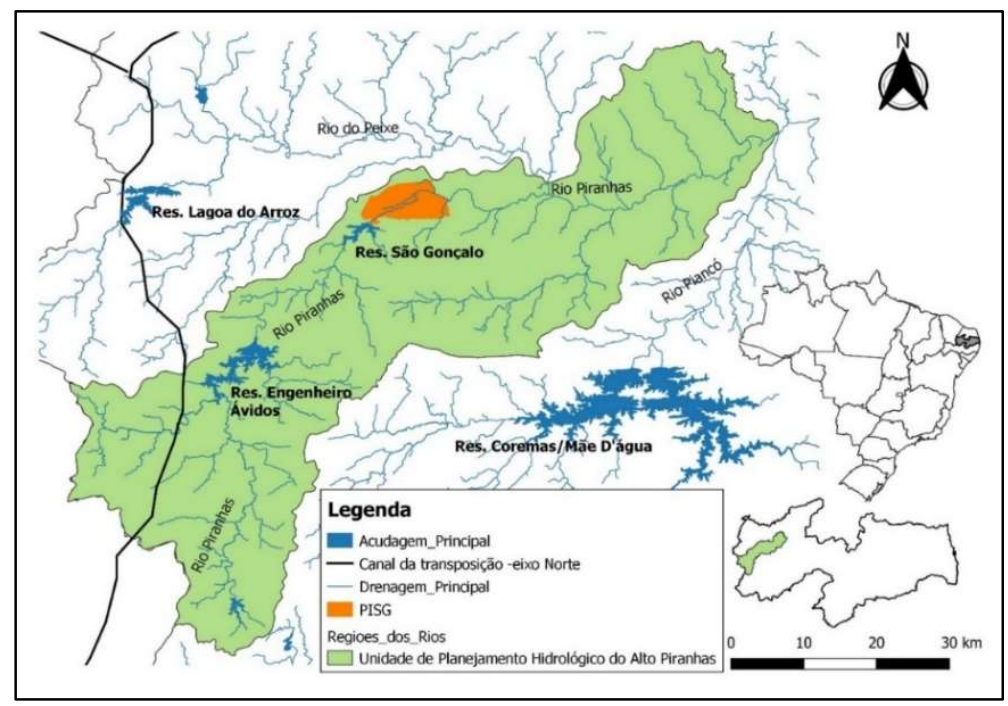

Figura 1: Localização da Unidade de Planejamento Hidrológico do Alto Piranhas (UPHAP).

Tais reservatórios são responsáveis pelo abastecimento de água de duas importantes cidades paraibanas, Cajazeiras - PB e Sousa - PB, além das cidades de Marizópolis - PB, Nazarezinho - PB e dos distritos de Engenheiros Ávidos e São Gonçalo cuja população urbana é de aproximadamente 107.923 habitantes (IBGE, 2019), sendo utilizados também para suprir as demandas hídricas do Perímetro Irrigado de São Gonçalo (PISG), que possui uma área total de 3.139 ha, e as demandas difusas ao longo do Rio Piranhas e no entorno do reservatório São Gonçalo (REIS et al., 2019).

Segundo o Plano de Recursos Hídricos da Bacia Hidrográfica do Rio Piancó-Piranhas-Açu (ANA, 2016) está previsto um aporte de água no reservatório Engenheiro Ávidos da ordem de 1,7 $\mathrm{m}^{3} / \mathrm{s}$ (vazão firme) proveniente do Eixo Norte do Projeto de Integração do Rio São Francisco.

Conforme a Nota Técnica nำ19/2004/NGI/ANA o curso superior do Rio Piranhas-Açu, a montante da confluência do Rio Piancó, compreende uma bacia totalmente contida no estado da Paraíba, o que faz com que todos os rios nesta sub-bacia, incluindo o próprio curso superior, sejam de dominialidade estadual 
paraibana (ANA, 2004). Portanto, as outorgas dos direitos de uso de recursos hídricos na UPHAP do Rio Piranhas são emitidas pela Agência Executiva de Gestão de Águas do Estado da Paraíba (AESA). Os reservatórios Engenheiro Ávidos e São Gonçalo, por outro lado, foram construídos e são administrados pelo Departamento Nacional de Obras Contra as Secas (DNOCS), órgão federal, e, portanto, suas águas são domínio da União, logo as outorgas dos direitos de uso de recursos hídricos desses reservatórios são emitidas pela Agência Nacional de Águas (ANA). Os principais usuários de água do sistema são apresentados na Figura 2.

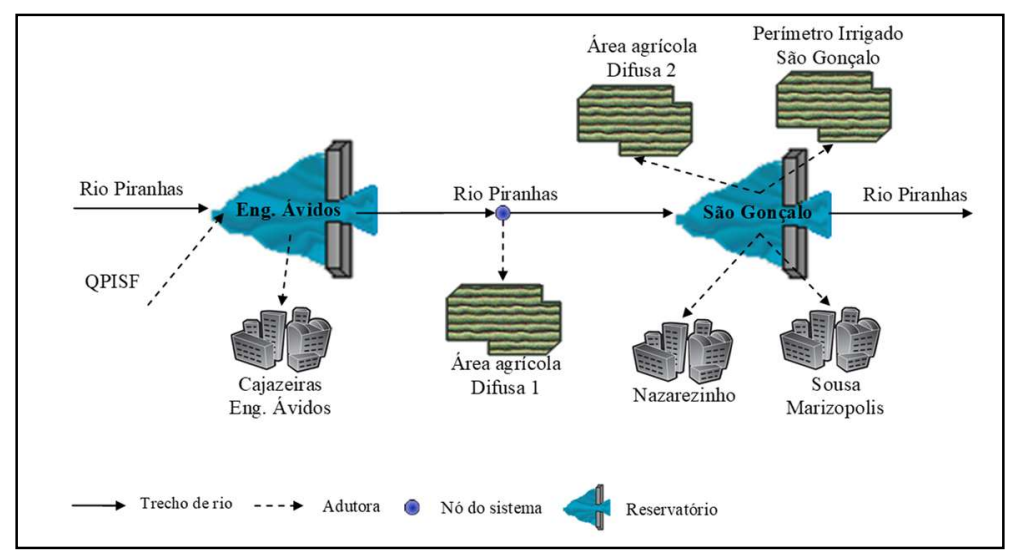

Figura 2: Layout do sistema estudado.

Os valores das vazões das outorgas emitidas para a Companhia de Água e Esgotos da Paraíba (CAGEPA) para efetuar o abastecimento dos núcleos urbanos podem ser observados na Tabela 1. Segundo a AESA (2017), na área agrícola difusa 1, situado no leito do rio Piranhas entre os dois reservatórios, existem 14 outorgas emitidas para fins de irrigação. Além disso, há 63 outorgas para a irrigação na área agrícola difusa 2, situada nas margens do reservatório São Gonçalo, conforme as Resoluções ANA № 1138 de 06 de setembro de 2013; № 613, № 614 e № 615 de 11 de abril de 2014.

Tabela 1: Valor da vazão outorgada para o abastecimento dos núcleos urbanos.

\begin{tabular}{ll}
\hline Núcleos urbanos & Vazão outorgada $\left(\mathbf{m}^{\mathbf{3}} / \mathbf{h}\right)$ \\
\hline Cajazeiras - PB e distrito de Engenheiro Ávidos & 663,16 \\
Sousa - PB, Marizópolis - PB e o distrito de São Gonçalo & 573,98 \\
Nazarezinho - PB & 25,85 \\
\hline
\end{tabular}

Fonte: ANA (2017).

Outro importante usuário de água é o PISG, que possuía uma área irrigável, no ano de 2012, de cerca 2600 ha. Não existi nenhuma outorga emitida pela ANA aos colonos do PISG, porém desde janeiro de 2013 não há retirada de água do reservatório São Gonçalo para atendimento da demanda hídrica das culturas agrícolas do perímetro, sendo que em 2015 o mesmo foi desativado devido à grave seca que ocorreu na região.

\section{Otimização Multiobjetivo}

Com o objetivo de determinar o volume de água mensal dos reservatórios, a garantia de atendimentos das outorgas, o volume fornecido para os usuários outorgados e o volume de saída a jusante do sistema em cada mês (no cenário C2) foi utilizado o modelo de otimização quantitativa desenvolvido por 
Novo modelo de cobrança para o uso de recursos hídricos em bacias de rio controladas por reservatórios: aplicação no sistema Engenheiro

Santos et al. (2011).

O modelo é baseado em programação linear utilizando o Toolbox Optimization do software MATLAB com o Método do Ponto Interior para a busca da solução ótima. Para tanto, linearizações apropriadas das não-linearidades intrínsecas aos processos de cada um de seus componentes tiveram que ser pesquisadas e implementadas através do uso combinado do Artifício de Linearização por Segmentos e da Programação Linear Sequencial.

Para realizar a otimização do sistema, envolvendo os 81 usuários cadastrados, foram observados os seguintes critérios operacionais para todos os cenários e situações propostas: O período de estudo corresponde a 10 (dez) anos, iniciando o processo de otimização no mês de janeiro de 2007 (A escolha da série histórica analisada, ocorreu em função da necessidade de captar características inerentes aos períodos de cheia e aos períodos de seca na região estudada); O volume de água inicial dos reservatórios Engenheiro Ávidos e São Gonçalo foram estabelecidos como sendo 62\% e 51\%, respectivamente, da capacidade dos mesmos, correspondente ao volume de água do dia 1 de janeiro 2007 segundo dados da AESA; O volume de água dos reservatórios, ao final do período de estudo, deve ser maior ou igual ao volume de água do dia 01 de janeiro de 2012 (antes do período seco); O volume meta dos reservatórios, em todos os meses, foi considerado igual à capacidade dos mesmos; Prioridades (em ordem crescente) de atendimento, em todos os cenários, foram: atendimento da demanda de abastecimento urbano; atendimento das demandas agrícolas e o atendimento do volume meta dos reservatórios; O reservatório São Gonçalo não tem um sistema de descarga de fundo, sendo sua construção prevista antes da chegada da vazão do PISRF, sendo nesse caso, considerado apenas no cenário $\mathrm{C} 2$.

Os dados estruturais (Tabela 2) e da cota-área-volume dos reservatórios estudados foram obtidos do Cadastro de Açude do Plano Diretor de Recursos Hídricos da Bacia do Alto Piranhas e Piancó (SCIENTEC, 1997).

Tabela 2: Dados estruturais dos reservatórios estudados.

\begin{tabular}{lll}
\hline & Engenheiro Ávidos & São Gonçalo \\
\hline Volume Máximo $\left(\mathrm{hm}^{3}\right)$ & 255,00 & 44,6 \\
Volume Morto $\left(\mathrm{hm}^{3}\right)$ & 7,97 & 2,97 \\
Vazão vertida máxima projetada $\left(\mathrm{m}^{3} / \mathrm{s}\right)$ & 1.610 & 1.800 \\
Diâmetro da seção transversal do tubo de descarga de fundo $(\mathrm{m})$ & 1,00 & 0,5 \\
Cota de entrada do tubo de descarga de fundo $(\mathrm{m})$ & 301 & 234 \\
\hline
\end{tabular}

Fonte: SCIENTEC (1997).

A vazão outorgável do PISG e a vazão medida dos usuários outorgados nas áreas agrícolas difusas forma estimadas por Silva Neto (2018). Considerou-se que a vazão medida do PISG e da CAGEPA são iguais aos seus valores outorgados.

Os dados de vazões afluentes aos reservatórios e nós do sistema foram gerados pelo o modelo hidrológico chuva x vazão SMAP, calibrado utilizando as séries de vazões do posto fluviométrico Piancó (ANA, 2016). Foram geradas as séries de deflúvios médios mensais de janeiro de 2007 a dezembro de 2016 a partir de dados de precipitação mensais. Os valores de precipitação mensais dos postos pluviométricos utilizados 
para a determinação da vazão afluente foram obtidos do banco de dados da AESA. As informações de evapotranspiração de referência para a determinação das vazões afluentes e os dados do Tanque Classe $A$ da Estação Climatológica de São Gonçalo para a determinação da evaporação nos reservatórios foram provenientes do Plano de Recursos Hídricos da BHRPPA (ANA, 2016). Os valores mensais do coeficiente de tanque foram estimados por Oliveira et al. (2005) para a região do sertão paraibano.

\section{RESULTADOS E DISCUSSÃO}

\section{Otimização quantitativa dos recursos hídricos do sistema}

A Tabela 3 apresenta as garantias de atendimento dos usuários outorgados em todos os cenários e situações analisadas no período estudado. Tem-se que o único usuário que apresentou falhas no atendimento foi o PISG, sendo mais acentuadas no cenário C1 (sem a vazão exógena do PIRSF). Destaca-se o fato, no cenário $\mathrm{C} 2$, que a vazão firme do PIRSF (cerca 1,7 m³ $/ \mathrm{s}$ ) prevista pelo Plano Diretor da BHRPPA (ANA, 2016) não foi suficiente para garantir o atendimento integral de todos os usuários do sistema.

Tabela 3: Garantia do atendimento das outorgas do sistema.

\begin{tabular}{|c|c|c|c|c|}
\hline Usuários outorgados & S1-C1 & S2-C1 & S1-C2 & S2-C2 \\
\hline CAGEPA (Cajazeiras - PB e distrito de Engenheiro Ávidos) & $100 \%$ & $100 \%$ & $100 \%$ & $100 \%$ \\
\hline CAGEPA (Sousa - PB, Marizópolis - PB e o distrito de São Gonçalo) & $100 \%$ & $100 \%$ & $100 \%$ & $100 \%$ \\
\hline CAGEPA (Nazarezinho - PB) & $100 \%$ & $100 \%$ & $100 \%$ & $100 \%$ \\
\hline Área agrícola difusa 1 (14 usuários outorgados) & $100 \%$ & $100 \%$ & $100 \%$ & $100 \%$ \\
\hline Área agrícola difusa 2 (63 usuários outorgados) & $100 \%$ & $100 \%$ & $100 \%$ & $100 \%$ \\
\hline PISG & $32,5 \%$ & $33,3 \%$ & $95,8 \%$ & $95,8 \%$ \\
\hline
\end{tabular}

A Figura 3 apresenta o comportamento do volume de água dos reservatórios do sistema para o período estudado em todos os cenários e situações analisadas.

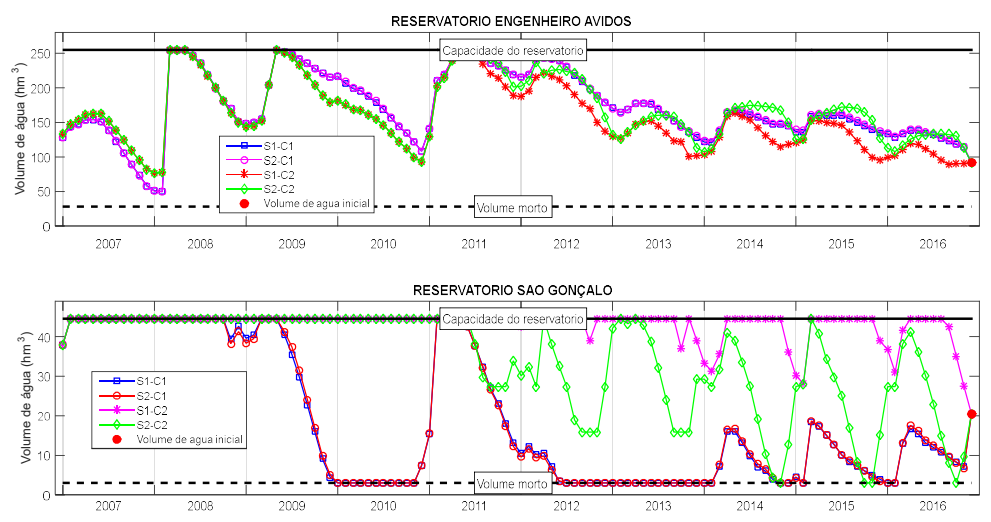

Figura 3: Comportamento do volume de água dos reservatórios do sistema.

Observa-se um comportamento similar no volume de água do reservatório Engenheiro Ávidos em todos os cenários e situações. Destaca-se o fato de que entre 2013 e 2016 o volume de água do reservatório sempre foi superior a 35\% da sua capacidade de armazenamento de água. Entretanto, o volume de água do reservatório de São Gonçalo apresenta comportamento distinto entre os cenários analisados. Enquanto que, no cenário C1, o volume de água do reservatório, em alguns anos (2007, 2008, 2009 e 2011), atinge a capacidade de armazenamento, em outros, atinge o volume morto (2010, de 2012 a 2016). No cenário C2, o 
Novo modelo de cobrança para o uso de recursos hídricos em bacias de rio controladas por reservatórios: aplicação no sistema Engenheiro

volume de água só atinge o volume morto na situação S2, sendo que na situação $\mathrm{S} 1$, em todos os anos o volume de água atingiu a capacidade de armazenamento. Vale destacar que de 2012 a 2016 a região passou pela maior seca dos últimos 50 anos.

A Figura 4 apresenta a vazão na saída do sistema no cenário C2. Tem-se que a vazão de saída do sistema foi maior que a vazão do PIRSF só quando ocorreram vertimentos no reservatório São Gonçalo. Entretanto de julho de 2011 não houve liberação de água para o Rio Piranhas. Tal situação é preocupante, haja vista que essa vazão exógena está projetada para atender outras demandas a jusante do sistema, como por exemplo, as demandas difusas ao longo do Rio Piranhas até o Rio Grande do Norte - RN.

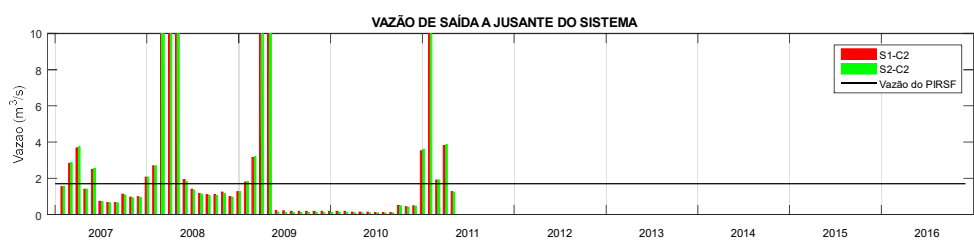

Figura 4: Vazão na saída do sistema no cenário C2.

Seleção dos usuários para a apresentação dos resultados, coeficientes de ponderação e Preços Públicos Unitários (PPUs) utilizados no processo de cobrança pelo uso dos recursos hídricos

Visando dar maior objetividade a análise e a apresentação dos resultados, além de melhor demonstrar as principais características do modelo de cobrança proposto por Silva Neto (2018), optou-se pela seleção intencional de 03 dentre as 80 outorgas de direito de uso dos recursos hídricos utilizados para o processo de simulação da cobrança como um todo (dados coletados junto a AESA e a ANA). Os usuários selecionados foram: 1. Ab_urb: (abastecimento urbano do município de Cajazeiras - PB), com outorga de $663,16 \mathrm{~m}^{3} / \mathrm{h}$, durante um período de $24 \mathrm{~h} /$ dia nos 365 dias do ano, e ponto de captação no reservatório Engenheiro Ávidos; 2. Irrigante_A: o maior volume outorgado dentre o total de usuários cadastrados, que, por sua vez, utiliza-se de irrigação localizada por microaspersão, com ponto de captação difuso localizado no leito do Rio Piranhas no trecho compreendido entre os reservatórios de Engenheiro Ávidos e São Gonçalo. A vazão horária outorgada desse usuário é de $29,8 \mathrm{~m}^{3} / \mathrm{h}$, para um período de $14,5 \mathrm{~h} /$ dia nos 365 dias do ano, para o cultivo de coco do tipo anão em uma área aproximada de 06 hectares; e, por fim, 3. Irrigante_B: que possui o menor volume outorgado dentre os demais usuários. Neste último caso, a tecnologia de irrigação utilizada é aspersão convencional com captação no reservatório de São Gonçalo e vazão horária outorgada de $17,5 \mathrm{~m}^{3} / \mathrm{h}$, durante $2 \mathrm{~h} /$ dia em 8 dias/mês para o cultivo de banana em uma área aproximada de 0,5 hectares, irrigando 8 dias/mês, $2 \mathrm{~h}$.

Além de atender a critérios, como o volume outorgado e o tipo de uso, a seleção dos usuários descritos acima levou em consideração, também, a disposição geográfica desses usuários no sistema, as características de medição, a utilização de tecnologias de irrigação diferenciadas, além de outros aspectos que tornaram possível evidenciar as características mais fortes do modelo de cobrança aplicado.

Em relação aos coeficientes de ponderação e PPUs utilizados na simulação da cobrança, a Tabela 4 apresenta os valores correspondentes para cada um dos usuários selecionados, considerando as situações 
analisadas. É importante frisar que o estabelecimento de valores para os coeficientes na simulação da cobrança no sistema levou em consideração as características inerentes de cada usuário. Além disso, foram consideradas, também, as características do sistema de recursos hídricos objeto de estudo.

Tabela 4: Coeficientes de ponderação para cada situação.

\begin{tabular}{|c|c|c|c|c|c|c|c|}
\hline \multirow{3}{*}{ VTC } & \multirow{3}{*}{ Coeficientes } & \multicolumn{6}{|c|}{ Situações/usuários } \\
\hline & & \multicolumn{3}{|c|}{ S1 } & \multicolumn{3}{|c|}{ S2 } \\
\hline & & Ab_Urb & Irrigante_A & Irrigante_B & Ab_Urb & Irrigante_A & Irrigante_B \\
\hline \multirow{6}{*}{$V_{\text {out }}$} & $Q_{\text {out }}\left(10^{3} \mathrm{~m}^{3}\right)$ & 484,1068 & 13,4100 & 0,2800 & 484,1068 & 13,4100 & 0,2800 \\
\hline & $P P U_{\text {out }}\left(R \$ / m^{3}\right)$ & 0,0120 & 0,0050 & 0,0050 & 0,0120 & 0,0050 & 0,0050 \\
\hline & $\mathrm{K}_{\mathrm{g}}$ & 1,0000 & 1,0000 & 1,0000 & 1,0000 & 1,0000 & 1,0000 \\
\hline & $\mathrm{K}_{\mathrm{e}}^{0}$ & 1,0000 & 0,5000 & 0,6000 & 1,0000 & 0,5000 & 0,6000 \\
\hline & $\mathrm{K}_{\mathrm{c}}$ & 1,0000 & 1,0000 & 1,0000 & 1,0000 & 1,0000 & 1,0000 \\
\hline & $\mathbf{F}_{\mathrm{m}}$ & 1,0000 & 1,0000 & 1,0000 & 0,5000 & 0,5000 & 0,5000 \\
\hline \multirow{3}{*}{$\mathrm{V}_{\text {cap }}$} & $P P U_{e x}\left(R \$ / m^{3}\right)$ & - & - & - & 0,0360 & 0,0150 & 0,0150 \\
\hline & $\mathrm{PPU}_{\mathrm{re}}\left(\mathrm{R} \$ / \mathrm{m}^{3}\right)$ & - & - & - & 0,0240 & 0,0100 & 0,0100 \\
\hline & $K_{\mathrm{var}}$ & - & - & - & 0,0500 & 0,3000 & 0,3000 \\
\hline \multirow{4}{*}{$\mathrm{V}_{\text {tra }}$} & $Q_{\text {tra_ent }}\left(10^{6} \mathrm{~m}^{3}\right)$ & 4,4064 & 4,4064 & 4,4064 & 4,4064 & 4,4064 & 4,4064 \\
\hline & $\mathrm{K}_{\mathrm{u}}$ & 0,0845 & 0,0023 & $4,888 \mathrm{E}-05$ & 0,0845 & 0,0023 & $4,888 \mathrm{E}-05$ \\
\hline & $\mathrm{PPU}_{\text {tra }}\left(\mathrm{R} \$ \mathrm{~m}^{3}\right)$ & 0,3000 & 0,3000 & 0,3000 & 0,3000 & 0,3000 & 0,3000 \\
\hline & Sub $\left(R \$ / m^{3}\right)$ & 0,2850 & 0,2850 & 0,2850 & 0,2850 & 0,2850 & 0,2850 \\
\hline \multirow{4}{*}{$\mathbf{V}_{\text {ges }}$} & $F_{g}$ & 0,4000 & 0,4000 & 0,4000 & 0,4000 & 0,4000 & 0,4000 \\
\hline & $V P L_{\text {inv }}\left(R \$ 10^{6}\right)$ & 25,0000 & 25,0000 & 25,0000 & 25,0000 & 25,0000 & 25,0000 \\
\hline & $\mathrm{n}$ & 120,0000 & 120,0000 & 120,0000 & 120,0000 & 120,0000 & 120,0000 \\
\hline & $\mathrm{K}_{\mathrm{u}}$ & 0,0845 & 0,0023 & $4,888 \mathrm{E}-05$ & 0,0845 & 0,0023 & $4,888 \mathrm{E}-05$ \\
\hline \multirow{4}{*}{$V_{\text {na }}$} & $B_{\text {na_v }}\left(R \$ / m^{3}\right)$ & 0,0030 & 0,0030 & 0,0030 & 0,0030 & 0,0030 & 0,0030 \\
\hline & $B_{n a \_a}\left(R \$ / m^{3}\right)$ & 0,0020 & 0,0020 & 0,0020 & 0,0020 & 0,0020 & 0,0020 \\
\hline & $B_{\text {na_v1 }}\left(R \$ / m^{3}\right)$ & 0,0010 & 0,0010 & 0,0010 & 0,0010 & 0,0010 & 0,0010 \\
\hline & $B_{\text {na_v2 }}\left(R \$ / m^{3}\right)$ & 0,0000 & 0,0000 & 0,0000 & 0,0000 & 0,0000 & 0,0000 \\
\hline
\end{tabular}

sendo PPU ex o preço público unitário por $\mathrm{m}^{3}$ quando a medição exceder o limite tolerado pelo Kvar (em \% de variação); $\mathrm{PPU}_{\text {re }}$ o preço público unitário por $\mathrm{m}^{3}$ quando a medição for inferior ao limite tolerado pelo Kvar (em \% de variação); Bna_v o valor da bandeira tarifária vermelha (em $\mathrm{R} \$$ )em relação ao nível de armazenamento de água do sistema; $B_{\text {na_a }} O$ valor da bandeira tarifária amarela(em R\$̧)em relação ao nível de armazenamento de água do sistema; Bna_v1 o valor da bandeira tarifária verde(em $\mathrm{R} \$$ ) nível 1 em relação ao nível de armazenamento de água do sistema e Bna_v2 o valor da bandeira tarifária verde(em R\$̣) nível 2 em relação ao nível de armazenamento de água do sistema.

\section{Análise da cobrança pelo uso dos recursos hídricos do cenário C1 na situação S1 e situação S2}

A Figura 5 apresenta os valores das componentes do VTC (Valor Total da Cobrança) para o usuário do abastecimento urbano (vazão outorgada de $663,16 \mathrm{~m}^{3} / \mathrm{h}$ ).

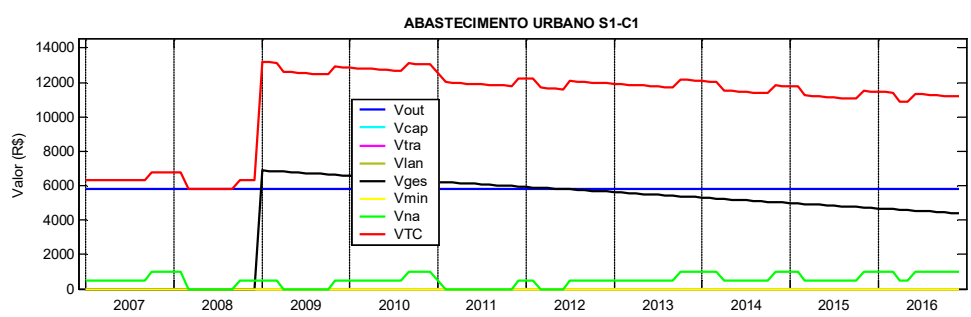

Figura 5: Componentes do VTC para o abastecimento urbano na situação S1 do cenário C1 (S1-C1).

Destaca-se que, dentre os elementos que compõe o VTC, neste caso, o valor do componente nível de armazenamento de água do sistema $\left(\mathrm{V}_{\text {na }}\right)$ e o valor da componente gestão $\left(\mathrm{V}_{\text {ges }}\right)$ foram determinantes para caracterizar o comportamento do VTC ao longo do tempo. Em relação ao valor do componente nível de armazenamento de água do sistema, pode-se dizer que este ditou praticamente as variações do VTC longo 
de todo o período analisado. A componente gestão, por sua vez, impulsionou o crescimento do valor cobrando de forma substancial a partir do segundo ano de cobrança (período pós-carência de pagamentos pela componente), porém apresentando um comportamento decrescente ao longo da série. Este aspecto ocorre em virtude de que, no horizonte temporal de 120 meses considerados para a realização de investimentos no sistema, não se considerou novas injeções de recursos na bacia e sim apenas os investimentos previstos inicialmente para todo o período.

Assim, o VTC apresentou, relativamente uma taxa de variação decrescente ao longo do período analisado em função da componente gestão, o que, de certa forma, reflete o impacto da amortização (ou participação proporcional nos usuários nos investimentos projetados) dos investimentos planejados em relação ao volume bruto arrecadado com a cobrança.

Em relação à situação S2 (Figura 6), o comportamento dos componentes do VTC do abastecimento urbano é similar ao da situação S1, porém com uma diferença básica entre os valores obtidos. Na situação S1 os valores mensais situaram-se em torno da faixa que vai de $R \$ 10.000,00$ a $R \$ 14.000,00$, enquanto que na situação S2 essa faixa de valores cai para um intervalo entre $\mathrm{R} \$ \mathbf{8 . 0 0 0 , 0 0}$ e $10.500,00$. Isso pode ser explicado pelo impacto que a utilização do medidor de vazão provoca na redução dos custos.

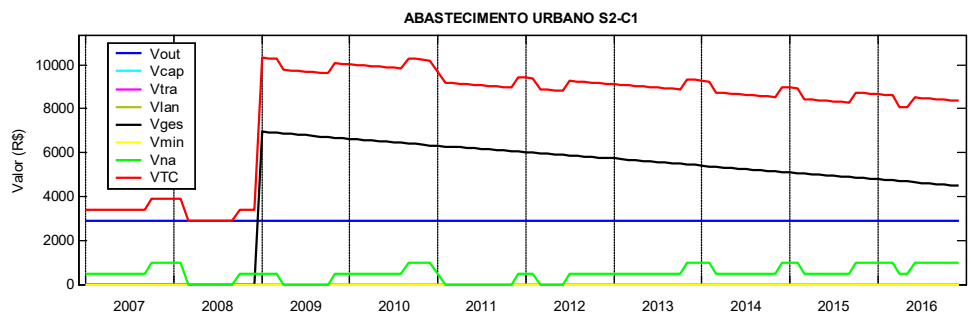

Figura 6: Componentes do VTC para o abastecimento urbano na situação S2do cenário C1 (S2-C1).

Levando-se em conta o maior valor para VTC da série temporal do abastecimento urbano na situação S1 (janeiro de 2009, conforme Figura 5), que atingiu o valor de $\mathrm{R} \$ 13.185,15$ para um volume outorgado de $484.106,8 \mathrm{~m}^{3} / \mathrm{mês}$, pode-se dizer que o valor do metro cúbico foi aproximadamente de $\mathrm{R} \$ 0,027$, enquanto que na situação $S 2$ foi de $R \$ 0,021$, para um VTC de $R \$ 10.331,10$ no mesmo período (ver Figura 6). Portanto, observa-se que a utilização do medidor de vazão gera uma redução do VTC, o que, de certa forma, representa um mecanismo incitativo para a utilização da medição de vazão, que, por sua vez, permite um melhor gerenciamento do processo como um todo, principalmente quando se tratar da agricultura, onde a variabilidade é elevada.

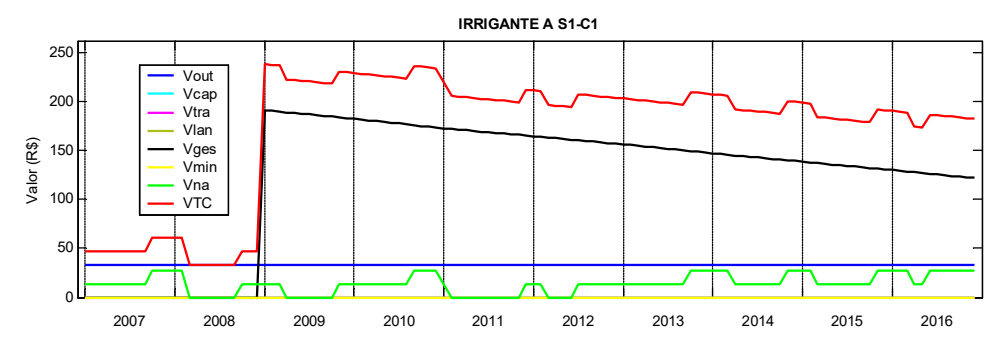

Figura 7: Componentes do VTC para o irrigante_A na situaçãoS1 do cenário C1(S1-C1)

No caso do irrigante_A, na situação S1 do cenário C1 a faixa de valores do VTC situou-se entre R\$ 
150,00 e $R \$ 250,00$, conforme demonstra o Figura 7.

Dado um volume outorgado para este usuário na ordem de $13.410 \mathrm{~m}^{3} / \mathrm{mês}$, o valor do metro cúbico saiu por R\$ 0,018 no mês onde o VTC atingiu o maior valor da série, que foi de R\$ 237,84 em janeiro de 2009. É importante frisar que, para o irrigante_A, assim como para o abastecimento urbano, o comportamento de ambos ao longo das séries na situação S1 foram semelhantes em relação ao VTC, ou seja, as variações foram ditadas tanto pelas variações no valor do componente nível de armazenamento de água do sistema quanto do valor da componente gestão, já que nessa situação (S1) os valores dependem do volume outorgado.

Em relação à situação S2 do cenário C1 (Figura 8), o comportamento do VTC para o irrigante_A apresentou algumas diferenças em relação à situação S1 do cenário C1 (Figura 7).

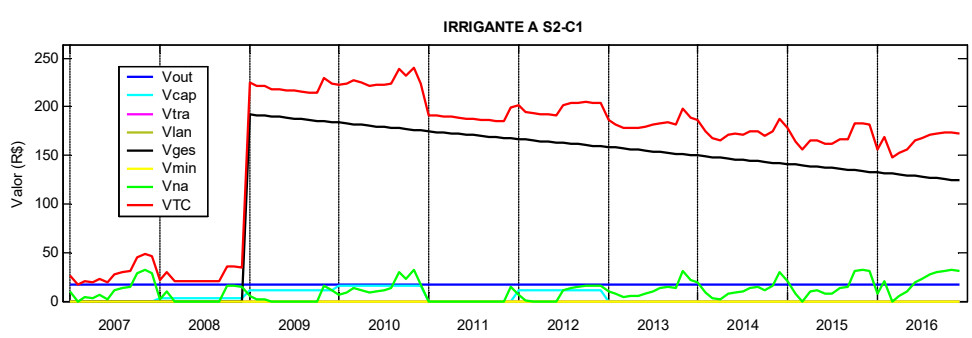

Figura 8: Componentes do VTC para o irrigante_A na situação S2do cenário C1 (S2-C1)

Observar-se que, ao longo da série, os valores assumidos apresentam uma maior variabilidade, além de situar-se em patamares menores em relação à situação anterior. Esta característica é resultado da utilização do medidor de vazão na situação S2, enquanto que a maior variabilidade ocorre em função do cálculo do componente nível de armazenamento de água do sistema, que por sua vez, passa a ser função da vazão medida via medidor de vazão, em detrimento da sua outorga. Esta é uma característica peculiar do modelo de cobrança para este caso já que apresenta uma diferença significativa em relação ao VTC.

No caso do irrigante_B, conforme as Figuras 9 e 10, um comportamento diferenciado em relação ao VTC dos demais usuários decritos anteriormente só é observadona situação S2, haja vista a utilização do medidor de vazão, assim como pelo fato deste usuário ter apresentado uma variabilidade relativamente muitoelevada. Isto se deve ao fato de que as medições ocorreram muito acima (ou abaixo) do volume outorgado de forma a ampliar o custo da componente captação.

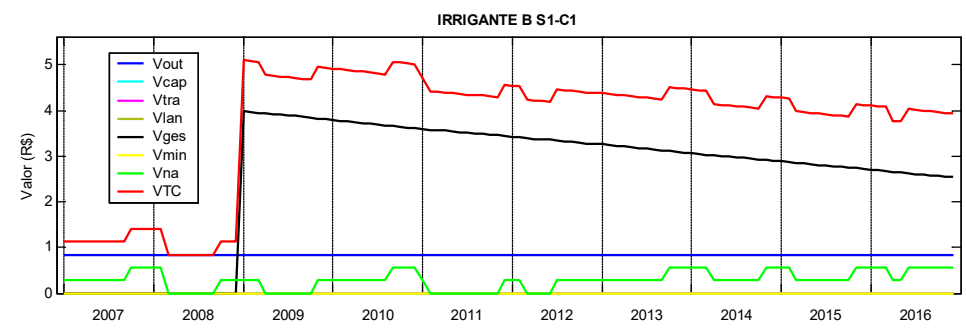

Figura 9: Componentes do VTC para o irrigante_Bna situação S1 do cenário C1 (S1-C1). 


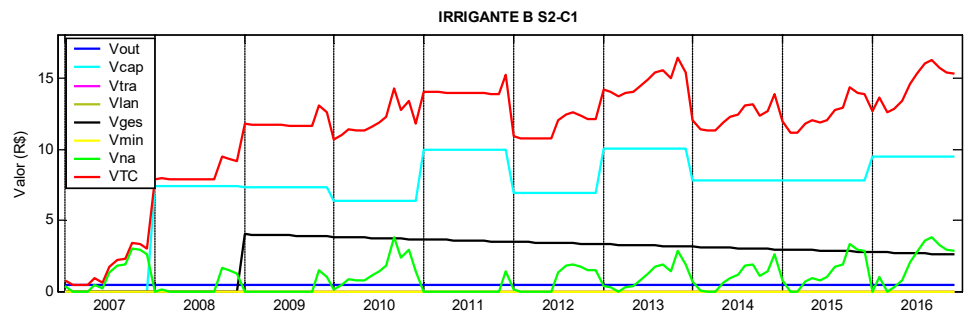

Figura 10: Componentes do VTC para o irrigante_B na situação S2 do cenário C1 (S2-C1).

Percebe-se então, conforme Figura 10, que o irrigante_B acaba sendo penalizado em relação à situação S1 (ver Figura 9), pois ao utilizar o medidor de vazão o VTC passa de um intervalo entre R\$ 4,00 e R\$ 5,00 na maior parte da série na situação $S 1$, para valores na situação $S 2$ entre $R \$ 8,00$ e $R \$ 17,00$. Tal aspecto demonstra o poder de penalização que o modelo de cobrança exerce sobre aqueles usuários que não adéquam o uso dos recursos hídricos ao volume outorgado. Diante de tal aspecto, o VTC passa a ficar mais elevado, já que neste caso a componente captação e a componente nível de armazenamento de água do sistema ditam a amplitude e a variabilidade do valor.

Mais especificamente em relação à componente captação, tem-se que os aspectos de reserva hídrica ampliam a variabilidade quando comparado ao irrigante_A. Isso se deve, haja vista que o modelo de cobrança proposto penaliza usuários via elevação dos custos quando estes utilizam um volume muito acima ou abaixo do volume outorgado para o caso da irrigação, dado o intervalo de variabilidade admitido.

Comparativamente, enquanto que na situação S1 o valor do metro cúbico foi de aproximadamente $\mathrm{R} \$ 0,018$ em relação ao maior valor do VTC (R\$ 5,11 em janeiro de 2009) da série histórica, na situação S2 o valor do metro cúbico foi de aproximadamente R\$ 0,059 para um VTC de R\$ 16,46 em novembro de 2013. Como o irrigante_B apresentou um volume medido relativamente diferente da sua outorga ao longo da série, na situação S2, o VTC ficou praticamente condicionado ao valor da componente captação e ao valor do componente nível de armazenamento de água do sistema, assim como apresentou um comportamento crescente ao longo da série analisada, diferentemente do que aconteceu nos casos anteriores onde os valores medidos situaram-se dentro das margens de variabilidade na captação, admitidas no modelo.

\section{Análise da cobrança pelo uso dos recursos hídricos do cenário C2 na situação S1 e situação S2}

Conforme se observa nas Figuras 11 e 12, o VTC para o abastecimento urbano apresenta comportamento semelhante às variações as ocorridas no valor da componente transposição $\left(V_{\text {tra }}\right)$.

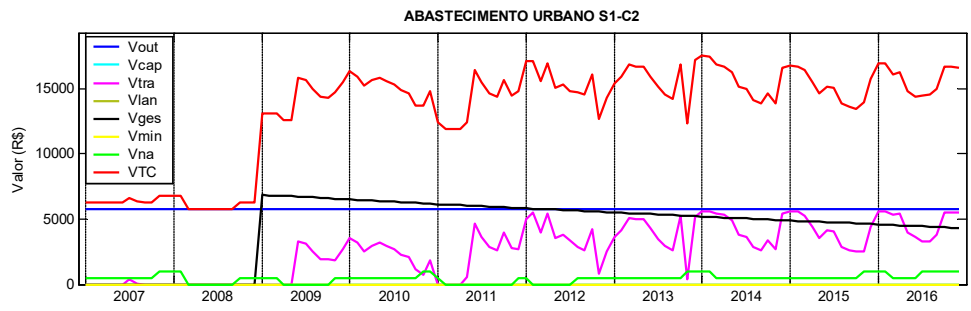

Figura 11: Componentes do VTC para o abastecimento urbano na situação S1, do cenário C2 (S1-C2). 


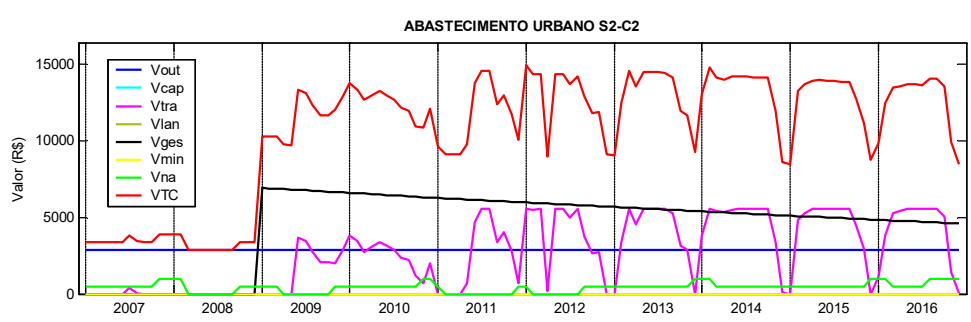

Figura 12: Componentes do VTC para o abastecimento urbano na situação S2, do cenário C2 (S2-C2).

Além destes aspectos, cabe destacar também que na situação S1 do cenário C2 os valores máximos do VTC giraram em torno dos R\$ $16.0000,00$, enquanto que na situação S2 do cenário C2 esses valores situaram-se na casa dosR $\$ 14.000,00$.

Tudo isso se explica pelo fato de que para o cálculo do valor da componente transposição, o modelo de cobrança leva em conta o valor do metro cúbico da transposição a ser pago ao comitê de bacia doadora, no caso, ao comitê de bacia do Rio São Francisco. Além desse aspecto, é importante frisar também que foi considerada a existência de subsídios, amenizando assim o impacto do custo da transposição sobre o VTC. Daí uma importância peculiar do modelo de cobrança proposto por Silva Neto (2018) ao considerar para o cálculo do custo da transposição uma parcela de desconto sobre o valor do metro cúbico da transposição sob a forma de subsídios governamentais.

Comparando as Figuras 11 e 12, pode-se observar inicialmente, que a diferença básica entre as duas situações analisadas (S1 e S2) neste cenário repousa no fato de que a presença da medição de vazão faz com que os valores atinjam patamares menores na situação S2. Outra questão também a se destacar em relação à situação anterior é que o comportamento do custo da transposição muda ao longo do tempo, haja vista as mudanças no cálculo geradas pela nova situação (S2-C2).

Isto ocorre em função dos usuários de irrigação, que na situação S1 tem o cálculo baseado no volume outorgado, enquanto que na situação S2, esse é função do volume medido. Logo, este aspecto acaba provocando alterações no cálculo do volume de recursos hídricos de saída do sistema, quando do processo de otimização quantitativa multiobjectivo, alterando assim o valor da componente transposição. Este fato pode ser melhor observado quando analisamos o comportamento da componente transposição em cada uma das situações consideradas.

No caso do irrigante_A, conforme destacam as Figuras 13 e 14, observa-se um aumento substancial em relação a variabilidade e a amplitude dos VTCs quando comparados com as mesmas situações do cenário C1. Na situação S2 do cenário C2, o comportamento o VTC para o irrigante_A é praticamente ditado pelas variações do valor da componente transposição. Pode-se observar, conforme Figura 14, que, em longos períodos de estiagem na região (2013, 2014, 2015 e 2016), os intervalos entre os picos do VTC ficam mais prolongados, ao contrário do que ocorre nos períodos mais chuvosos onde a variabilidade aumenta em função do volume acumulado no sistema de recursos hídricos considerado. Este aspecto pode ser considerado como mais um elemento importante do modelo de cobrança proposto pelo autor, já que permite vincular a característica sazonal do sistema de recursos hídricos ao VTC. Fato este que não é identificado em nenhum dos modelos de cobrança implantado no Brasil. 


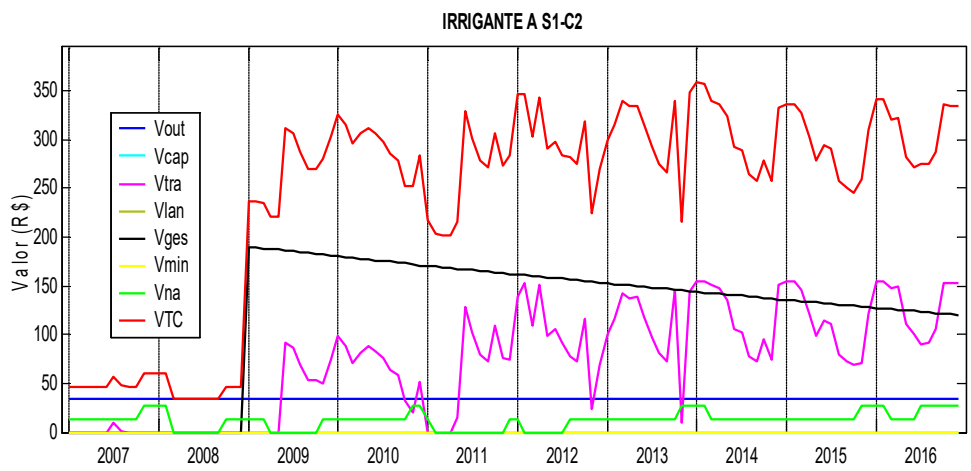

Figura 13: Componentes do VTC para o irrigante_A na situação S1 do cenário C2 (S1-C2).

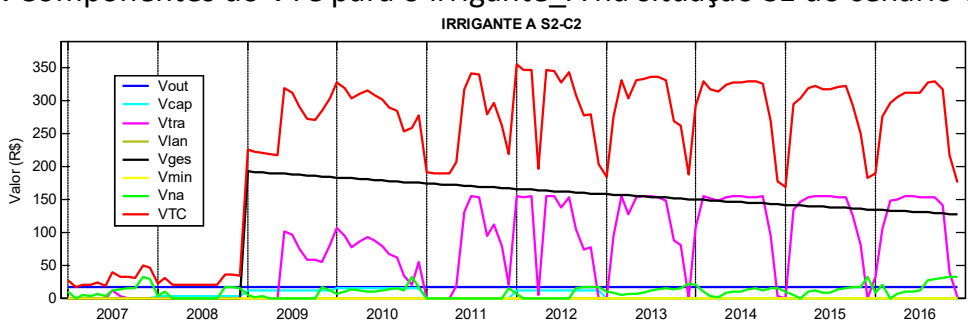

Figura 14: Componentes do VTC para o irrigante_A na situação S2 do cenário C2 (S2-C2).

Os valores do VTC do irrigante_A giraram em torno do intervalo entre $R \$ 200,00$ e $R \$ 350,00$ nas duas situações durante quase todo o período, atingindo seu valor máximo no início de 2014 na situação S1 $(R \$ 358,85)$, sendo o valor do metro cúbico de $R \$ 0,027$. Já na situação $S 2$, o valor máximo foi atingido em janeiro de 2012 (R\$ 354,88), cujo valor do metro cúbico é de $R \$ 0,026$.

A Figura 15 apresenta os resultados do irrigante_B na situação S1 do cenário C2. Neste caso, observase que o VTC é impulsionado principalmente pelo custo com a gestão e com a transposição, que por sua vez, dita a variabilidade ao longo do período. Os valores do VTC giraram em torno do intervalo entre $\mathrm{R} \$ 4,50$ e $\mathrm{R} \$$ 7,65 durante quase todo o período, atingindo seu valor máximo no início de 2014 (R\$̧7,63). Para esse período, o valor do metro cúbico foi de $\mathrm{R} \$ 0,027$.

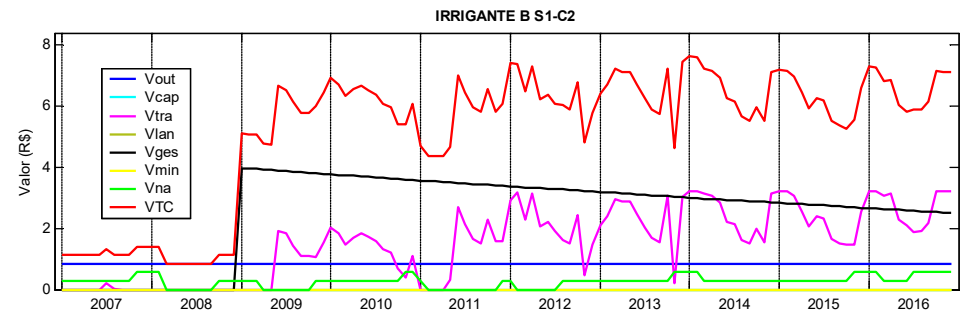

Figura 15 - Componentes do VTC para o irrigante_B na situação S1 do cenário C2 (S1-C2).

Na situação S2 do cenário C2 (Figura 16) o VTC do irrigante_B foi impulsionado principalmente pelo custo da transposição, pelo o custo da gestão e em maior intensidade pelo custo da captação, já que o usuário apresentou medições fora dos padrões admitidos pelo modelo em relação ao seu volume outorgado. Quanto à variabilidade, o comportamento do VTC acompanhou o comportamento tanto do valor da componente transposição, quanto do componente nível de armazenamento de água do sistema. 


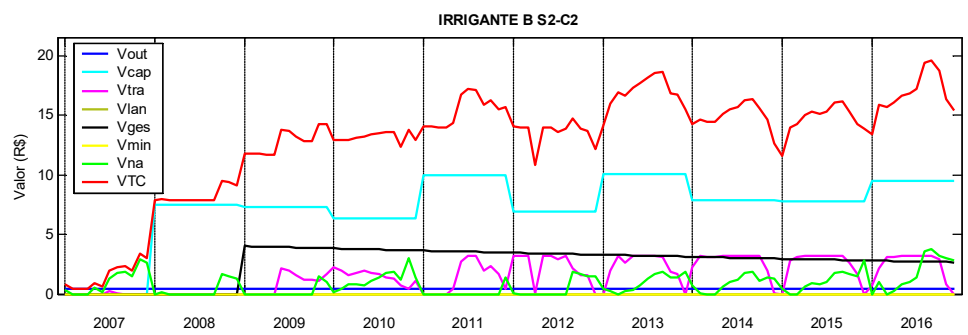

Figura 16: Componentes do VTC para o irrigante_B na situação S2 do cenário C2 (S2-C2).

É importante destacar também que mesmo tendo o seu custo reduzido em função da utilização de medidor de vazão, o irrigante_B foi penalizado em função das captações fora da variabilidade admitida em relação a sua outorga. O custo com a captação ampliou consideravelmente o VTC. Com isso percebe-se que a proposta de cobrança pelo uso dos recursos hídricos possui como característica importante a penalização de usuários que se beneficiam de reservas hídricas.

Os valores assumidos pelo VTC neste caso giraram em torno do intervalo entre $R \$ 5,00$ e $R \$ 20,00$ (ver Figura 16) durante quase todo o período, sendo o maior valor assumido pelo metro cúbico no mês de setembro de 2016 (auge do longo período de estiagem na região) de $\mathrm{R} \$$ 0,070 para um valor máximo do VTC de $R \$ 19,59$. Neste sentido, captações fora do padrão da outorga, principalmente em períodos de longa estiagem elevam significativamente o custo da água. Tudo isso, de certa forma, reflete claramente e objetivamente, além dos outros aspectos já mencionados, a capacidade que a proposta de cobrança de Silva Neto (2018) possui ao induzir o uso racional dos recursos hídricos.

\section{CONCLUSÕES}

A partir dos dados contidos no cadastro das outorgas da AESA e da ANA, assim como dos dados obtidos no processo de otimização quantitativa do sistema de recursos hídricos, foi possível analisar, de forma integrada, as vazões fornecidas pelo sistema para o atendimento das outorgas, o volume dos reservatórios, bem como as vazões no trecho do rio entre os dois reservatórios, dentre outras; tornando possível assim, simular a proposta de cobrança pelo uso dos recursos hídricos de Silva Neto (2018) na UPHAP. Neste sentido, tem-se que: 1 . Os resultados obtidos demonstram que o modelo apresenta objetividade, principalmente ao vincular outorga e cobrança pelo uso dos recursos hídricos de forma direta no cálculo do VTC. Além disso, constatou-se também a sua viabilidade operacional, já que apresentou um desempenho transparente a partir de uma forma explícita de cálculo; 2 . Foi possível verificar a capacidade do modelo de se adequar a diversas realidades e cenários, principalmente em se tratando da região semiárida. Para tanto, o modelo utilizou-se de aspectos como: tipos de usos; a utilização ou não de medição de vazão; a eficiência dos sistemas hidráulicos; a variabilidade admitida em função do uso para a captação etc.; 3. Foi possível verificar uma diferença entre os VTCs em função da existência ou não de medidor de vazão por parte dos diversos usuários. Sendo a ausência de medição um fator que onera o valor cobrado no caso dos usuários que possuem volumes captado dentro dos intervalos admitidos em relação ao seu volume outorgado (os casos dos usuários de abastecimento urbano e do irrigante_A); 4 . O modelo foi capaz de penalizar usuários 
(o caso do irrigante_B) que se utilizaram do uso de reservas hídricas e/ou uso além do volume outorgado, induzindo de certa forma o uso mais racional através de parcimônia; 5 . 0 uso de bandeiras tarifárias baseadas nas características sazonais do sistema hídrico amplia a variabilidade e valor do VTC principalmente em período de estiagem (2012 a2016) e quando o usuário faz uso do medidor de vazão, intensificando caso os usuários realizem captações fora dos intervalos admitidos em relação ao seu volume outorgado (o caso do irrigante_B); 6. O uso da componente gestão, além de reduzir a necessidade de captações externas de recursos financeiros para a realização de investimentos na bacia hidrográfica, onera o VTC, sendo decrescente ao longo do tempo caso não ocorram novas necessidades de aporte de recursos para investimentos; 7. O modelo pode ser devidamente apresentado e debatido no âmbito do CBH, sendo possível redimensionar os valores dos parâmetros utilizados visando um processo mais participativo e democrático, resolvendo assim o problema da ausência do instrumento da cobrança dos recursos hídricos na bacia hidrográfica objeto de estudo, conforme normatiza a Lei 9.433/97.

\section{REFERÊNCIAS}

ACSELRAD, M. V.; AZEVEDO, J. P. S.; FORMIGA-JOHNSSON, R M.. Cobrança pelo uso da água no Estado do Rio de Janeiro, Brasil (2004-2013): histórico e desafios atuais. Revista Engenharia Sanitária e Ambiental, Rio de Janeiro, v.20, n.2, p.199-208, 2015. DOI: http://doi.org/10.1590/S1413$\underline{41522015020000112026}$

AESA. Agência Executiva de Gestão das Águas do Estado da Paraíba. Quadro Resumo dos usuários da bacia da região do alto curso do rio Piranhas. Consultas de Outorgas. João Pessoa: AESA, 2017.

ANA. Agência Nacional de Águas. Planilhas de outorgas. Outorgas Emitidas. Brasília: ANA, 2017.

ANA. Agência Nacional de Águas. Plano de recursos hídricos da bacia hidrográfica do Rio Piancó-Piranhas-Açu. Brasília: ANA, 2016.

ANA. Agência Nacional de Águas. Cobrança pelo uso de recursos hídricos. Capacitação em Gestão de Recursos Hídricos. Brasília: SAG, 2014.

ANA. Agência Nacional de Águas. Nota Técnica $\mathbf{n}$. 019/2004/NGI/ANA. Nota Técnica referente ao Ofício DP/419/2004 (Governo do Estado da Paraíba). Brasília: NGI, 2004.

FINKLER, N. R.; MENDES, L. A.; BORTOLIN, T. A.; SCHNEIDER, V. E.. Cobrança pelo uso da água no Brasil: uma revisão metodológica. Revista Desenvolvimento e Meio Ambiente, Curitiba, v.33, p.33-49, 2015.DOI: http://doi.org/10.5380/dma.v33i0.36413

DIAS, T. F.; BARROS, H. O. M.; SOUZA, W. J.. Cobrança pelo uso da água: visões a partir dos membros do comitê de bacia hidrográfica do Rio Pirapama-Pernambuco. Revista Alcance. Biguaçu, v.17, n.4, p.416-432, 2010. DOI: http://dx.doi.org/10.14210/alcance.v17n4.p416-432
GAMA ENGENHARIA. Gama Engenharia e Recursos Hídricos Ltda. Atualização da metodologia de cobrança pelo uso de recursos hídricos na bacia hidrográfica do Rio São Francisco. Produto 1: revisão sobre metodologias de cobrança. Maceió: CBHSF, 2016.

HARTMANN, P.. A cobrança pelo uso da água como instrumento econômico na Política Ambiental: estudo comparativo e avaliação econômica dos modelos de cobrança pelo uso da água bruta propostos e implementados no Brasil. Porto Alegre: AEBA, 2010.

IBGE. Instituto Brasileiro de Geografia e Estatística. Censo 2010. Rio de Janeiro: IBGE, 2019.

OCDE. Organização Para a Cooperação e Desenvolvimento Econômico. Cobrança pelo uso de recursos hídricos no Brasil: caminhos a seguir. Paris: Éditions OCDE, 2017. DOI: http://dx.doi.org/10.1787/9789264288423-pt

OLIVEIRA, G. M.; LEITÃO, M. M. V. B. R.; GALVÃO, C. O.; LEITÃO, T. H. V.. Estimativa da Evaporação e Analise de Uso do Coeficiente (kp) do Tanque "Classe A" nas Regiões do Cariri e Sertão da Paraíba. Revista Brasileira de Recursos Hídricos, Porto Alegre, v.10, n.4, p.73-83, 2005. DOI: http://doi.org/10.21168/rbrh.v10n4.p73-83

REIS, C. Q.; SANTOS, V. S.; FARIAS, C. A. S.. Avaliação da sustentabilidade hídrica dos reservatórios Engenheiro Ávidos e São Gonçalo. Revista Brasileira de Gestão Ambiental, Pombal, v.13, n.2, p.01-09, 2019.

SANTOS, V. S.; CURI, W.F.; CURI, R. C.; VIEIRA, A. S.. Um Modelo de Otimização Multiobjetivo para Análise de Sistema de Recursos Hídricos I: Metodologia. Revista Brasileira de Recursos Hídricos, Porto Alegre, v.16, n.4, p.49-60, 2011. DOI: http://doi.org/10.21168/rbrh.v16n4.p49-60

SOUSA, F. R.; ASSIS, L. F.; VIEIRA, A. L.. Modelo de cobrança pelo uso da água: análise da arrecadação na sub-bacia do 
Alto Piranhas (PB). Revista Ibero-Americana de Ciências Ambientais, Aracaju, v. 6, n. 1, p. 246-261, 2015. DOI: http://dx.doi.org/10.6008/SPC2179-6858.2015.001.0019

SCIENTEC. Associação para Desenvolvimento da Ciência e Tecnologia. Plano Diretor de Recursos Hídricos da Paraíba: Bacias do Rio Piancó e do Alto Piranhas. João Pessoa: SEPLAN, 1997.

SILVA NETO, E. D.. Modelo de cobrança pelo uso dos recursos hídricos em sistemas controlados por reservatórios. Tese (Doutorado em Recursos Naturais) Universidade Federal de Campina Grande, Campina Grande, 2018.
THOMAS, P. T.. Proposta de uma Metodologia de Cobrança pelo Uso da Água vinculada à Escassez. Tese (Mestrado em Ciências em Engenharia Civil) - Universidade Federal do Rio de Janeiro, Rio de Janeiro, 2002.

VERA, L. H. A.; MONTENEGRO, S. M. G. L.; SILVA, S. R.. Performance of water usage charge in the Nation's domain as a water resource management tool in the São Francisco River basin. Revista Brasileira de Recursos Hídricos, Porto Alegre, v.22, n.7, 2017. DOI:

http://dx.doi.org/10.1590/2318-0331.011715171

A CBPC - Companhia Brasileira de Produção Científica (CNPJ: 11.221.422/0001-03) detém os direitos materiais desta publicação. Os direitos referem-se à publicação do trabalho em qualquer parte do mundo, incluindo os direitos às renovações, expansões e disseminações da contribuição, bem como outros direitos subsidiários. Todos os trabalhos publicados eletronicamente poderão posteriormente ser publicados em coletâneas impressas sob coordenação da Sustenere Publishing, da Companhia Brasileira de Produção Científica e seus parceiros autorizados. Os (as) autores (as) posteriormente ser publicados em coletâneas impressas sob coordenação da Sustenere Publishing, da Companhia Brasileira de Produção Cientifica e seus parce 